\title{
Cycling to work in London and inhaled dose of black carbon
}

\author{
Chinedu Nwokoro, Clare Ewin, Clare Harrison, Mubin Ibrahim, Isobel Dundas, \\ lain Dickson, Naseem Mushtaq and Jonathan Grigg
}

ABSTRACT: Modelling studies suggest that urban cycling is associated with an increased inhaled dose of fossil fuel-derived black carbon (BC). Using the amount of black material in airway macrophages as a marker of long-term inhaled BC, we sought to compare inhaled BC dose in London (UK) cyclists and non-cyclists.

Airway macrophage carbon was assessed in $28(58 \%)$ out of 48 healthy adults ( 14 cyclists and 14 non-cyclists) who attended for induced sputum. Short-term $(24 \mathrm{~h})$ exposure to BC was assessed on a representative working day in 27 out of 28 subjects. Serum interleukin (IL)-1ß, IL-2, IL-6, IL-8, granulocyte-macrophage colony-stimulating factor and tumour necrosis factor (TNF)-0 were assessed in 26 out of the 28 subjects.

Cyclists were found to have increased airway macrophage carbon when compared with noncyclists (mean $\pm \mathrm{SE} 1.81 \pm 0.21$ versus $1.11 \pm 0.07 \mu \mathrm{m}^{2} ; \mathrm{p}<0.01$ ). Short-term monitoring showed no difference in $24 \mathrm{~h}$ BC exposure between the two groups. However, cyclists were exposed to higher concentrations of $B C$ during commuting $(p<0.01)$. Airway macrophage carbon was associated with monitored commute $B C(n=28 ; r=0.47, p<0.05)$. TNF- $\alpha$ was found to be increased in cyclists $(p<0.05)$, but no other cytokines were increased.

Commuting to work by bicycle in London is associated with increased long-term inhaled dose of BC. Whether cycling per se increases inhaled BC dose remains unclear.

KEYWORDS: Airway macrophage carbon, commuting, cycling, personal black carbon

I nhalation of particulate matter (PM) from fossil fuel combustion is associated with adverse health effects, including reduced lung function [1] and increased mortality [2]. Although the mechanism for PM-induced health effects is not fully defined, animal models and in vitro studies suggest that pro-inflammatory cytokine release from airway cells is an important factor [3]. Fossil fuel-derived PM in the inhalable size range $(<10 \mu \mathrm{m}$ in aerodynamic diameter (PM10)) is dominated by aggregates of nanoparticles of elemental black carbon (BC) [4]. Variation in BC concentrations within cities, therefore, mirrors local variations in the concentration of fossil fuelderived PM10 [5]. For example, zones of high BC and PM10 occur along urban main roads [6]. Thus the distance of the home to the nearest main road is widely used as a marker of individual exposure to either BC or PM10 in epidemiological studies [7, 8]. However, individuals are also exposed to BC when using roads to travel to work [6] (fig. 1). Indeed, there is concern that commuting to work on a bicycle, by combining increased minute ventilation $\left(V^{\prime} \mathrm{E}\right)$ [9] and increased commuting time with the proximity to freshly generated exhaust fumes, significantly increases the inhaled dose of $\mathrm{BC}[10,11]$.

To date, the effect of commuting on inhaled BC dose is unknown. Recently, we developed a method for assessing the long-term inhaled dose of BC using the capacity of lower airway macrophages (AMs) to retain inhaled $\mathrm{BC}$ in a dosedependent manner over long periods of time [12]. In adolescents, we previously reported an inverse association between area of carbon in AMs (AM carbon) and lung function [13]. Other groups have reported an association between AM carbon and surrogate markers for cardiovascular disease in diabetic adults [14, 15]. In this study we hypothesised that, compared with individuals commuting by public transport, regular cycling to work exposes individuals to prolonged and high concentrations of $\mathrm{BC}$, resulting in an increased lower

\section{AFFILIATIONS}

Centre for Paediatrics, Blizard Institute, Barts and the London School of Medicine and Dentistry, Queen Mary University of London, London, UK.

CORRESPONDENCE

J. Grigg

Blizard Institute

Barts and the London School of

Medicine and Dentistry

Queen Mary University London

4 Newark Street

London

E1 2AT

UK

E-mail: j.grigg@qmul.ac.uk

Received:

Nov 102011

Accepted after revision:

Jan 292012

First published online:

Feb 232012 


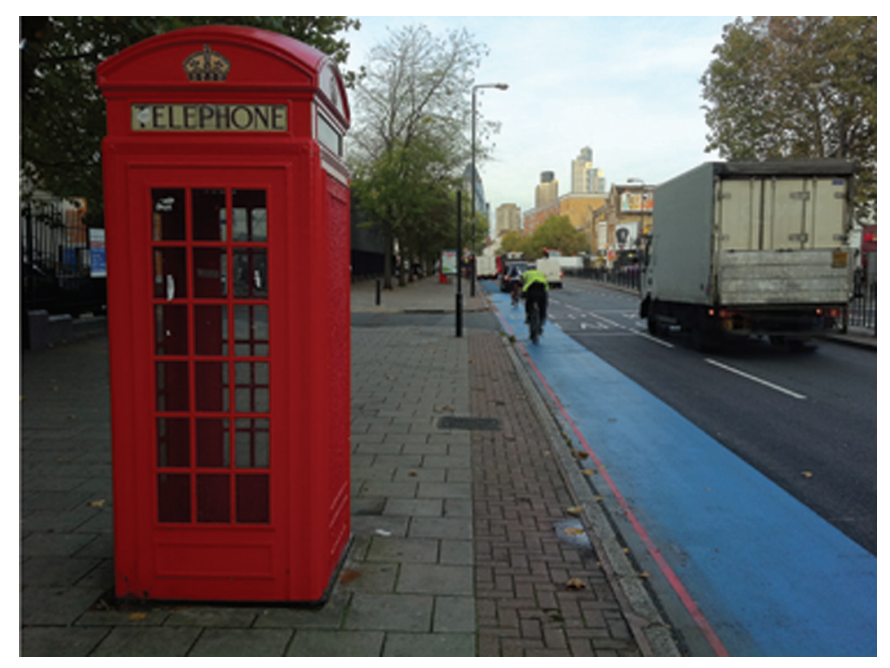

FIGURE 1. A cycle lane as depicted by the blue painted area on the side of the road in the east end of London (UK). Cyclists commute close to vehicles.

airway dose of $\mathrm{BC}$. We sought to test this hypothesis using a combination of AM carbon measurement and personal BC monitoring in healthy adults who either exclusively cycled to work in London (UK), or exclusively used public transport and/ or walking [16]. We also sought to compare systemic proinflammatory cytokines in the two groups.

\section{MATERIALS AND METHODS}

\section{Subjects}

The study's eligibility criteria were: aged 18-40 yrs, regularly commuting to work in either the east end of London or in central London for a minimum of 3 yrs, no history of personal smoking or domestic second-hand smoke exposure within the last 3 yrs, and no acute or chronic medical conditions. Exclusion criteria were: clinical respiratory infection within the previous 3 months, use of candles, wood or open fires in the home, and commuting to work by car. Car drivers were excluded since the majority of Londoners do not drive to work. Subjects were classified as cyclists if they habitually cycled from home to work. Non-cyclists were classified as individuals who commuted to work by either walking or public transport, or a combination of both. Subjects were studied from November 2010 through to March 2011. The local research ethics committee approved this study, and all subjects provided written consent.

\section{Questionnaire}

Subjects completed a questionnaire on smoking history, and usual mode of commute. Subjects' home postcodes were recorded and the distance of the home to the nearest main road (m) was calculated using Free Map Tools [17]. Briefly, the postcode of each subject's home was entered into the "quickfind" box on the website, and identified using the navigation tool. The nearest point on the closest major road (classified as an " $\mathrm{A}$ "-road) was then identified and the home main-road distance read from the "total distance" box.

\section{Lung function}

Lung function was measured using a MicroMedical MicroLab 3500 Spirometer Mk 8 (Cardinal Health UK, Basingstoke, UK) with a data management system compliant with American Thoracic Society guidelines [18]. Flow-volume loops were displayed for immediate quality control. Post-bronchodilator forced expiratory volume in $1 \mathrm{~s}$ (FEV1), forced vital capacity (FVC), forced expiratory flow at 25-75\% FVC and FEV1/FVC were recorded.

\section{Airway macrophage carbon}

Airway macrophages were obtained using sputum induction. Induced sputum was processed according to a standard technique [13]. After $0.1 \%$ dithiothreitol treatment to remove mucus (SigmaAldrich, Poole, UK), plugs of airway cells were identified and removed. Cells were cytocentrifuged (Cytospin; Shandon Scientific, Runcorn, UK) onto microscope slides and stained with DiffQuik (Dade Behring, Deerfield, IL, USA). Slides were analysed for AM carbon, as previously reported [13]. Briefly, digital colour images of AMs from random microscope fields were obtained from each subject using a Nikon digital camera and a Nikon Eclipse 80i microscope (Nikon Instruments, Amstelveen, the Netherlands) at x100 magnification. PictureFrame (Optronics, Goleta, CA, USA) was used to acquire the images. An image of a stage micrometer (S-12S stage micrometer, $0.1 \mathrm{~mm} / 50$ division; Pyser-SGI, Kent, UK) was also obtained at the same magnification. Image J (National Institute of Health, Bethesda, MD, USA) was used to analyse the AM images, with scaling calibrated using the image of the stage micrometre graticule. Each AM image was initially processed using Adobe Photoshop Elements (Adobe Systems Inc., San Jose, CA, USA). Each AM image was "cut and pasted," from a wide field image and the nucleus removed. The Image J software was used to measure the area of $\mathrm{BC}\left(\mu \mathrm{m}^{2}\right)$ within the AMs. The "threshold" command was adjusted to obtain the best fit of the black areas visible on the colour image. The area of carbon in each AM was calculated and the mean AM carbon $\left(\mu \mathrm{m}^{2}\right)$ was derived from 50 randomly selected AMs per subject, which were selected by an operator that had been blinded to commuting status.

\section{Monitored BC}

Personal exposure to $\mathrm{BC}$ was monitored using a portable aethalometer (Magee Scientific AE51, Berkeley, CA, USA) worn on a representative working day in subjects in whom sputum induction had produced sufficient AM for carbon analysis (i.e. some days after sputum induction). A representative working day was defined as one during a normal working week when the subject had a return journey between their normal place of work and their usual residence deemed to be typical of their habitual commuting behaviour. The aethalometer was carried on the waist during the day and when subjects moved around indoors. At night, the monitor was placed next to the bed. BC exposure was determined using the microAethCOM PC-based software application. The software output describes the mean concentration of $\mathrm{BC}\left(\mathrm{ng} \cdot \mathrm{m}^{-3}\right)$ for a predefined sampling period. In this study, the sampling time was set to $5 \mathrm{~min}$ and individual exposure was the sum of each 5-min BC concentration. This exposure metric is directly proportional to the area under the concentration time curve. BC exposure for the commute, at home and during other activities was then calculated using a time-activity diary completed on the day of monitoring. Background PM10 concentrations were obtained from a fixed air pollution monitoring station in a central London location (North 
Kensington) [19]. Meteorological data were obtained from a weather station in Greater London [20].

\section{Systemic cytokines}

Subjects underwent optional blood sampling after sputum induction. Blood was centrifuged and serum frozen at $-70^{\circ} \mathrm{C}$. Cytokines were defined a priori by their reported ability to be released by lung cells stimulated by PM10 in vivo, i.e. interleukin (IL)-1 $\beta$ [21, 22], IL-2 [23], IL-6 [22], IL-8 [21, 22], Granulocyte-macrophage colony-stimulating factor (GM-CSF) [21], and tumour necrosis factor (TNF)- $\alpha$ [24]. Serum cytokines were determined using a 96-Well Multi-Spot MS2400 Human ProInflammatory-9 plex Ultra-Sensitive Kit (Meso Scale Discovery, Gaithersburg, MD, USA). The plate was processed according to the manufacturer's instructions and read on the MSD SECTOR imager (Meso Scale Discovery). Data were analysed using the MSD Discovery Workbench Software (Meso Scale Discovery).

\section{Statistical analysis}

Data were analysed using IBM SPSS version 18.0 (Armonk, $\mathrm{NY}$, USA). Data are summarised as mean \pm SE. Comparisons were done using unpaired t-tests and expressed as the $95 \%$ confidence interval $(\mathrm{CI})$ of the difference and correlations done using Pearson correlation. A p value of $<0.05$ was considered significant.

\section{RESULTS}

48 adults attended for sputum induction. 28 (58\%) produced a sufficient number of AMs $(\geqslant 50)$ for assessment of carbon loading (14 cyclists and 14 non-cyclists). 26 out of 28 subjects agreed to blood sampling. Other than a small difference in weight, there were no significant demographic differences between subjects analysed $(n=28)$ and not analysed for AM carbon $(n=20)$ (table S1). Although a greater proportion of cycling subjects were male $(p<0.05)$ (table 1$)$, there were no significant differences in age, height, weight, home main-road distance, and post-bronchodilator lung function between cyclists and non-cyclists (table 1). Personal BC monitoring was performed in 27 out of the 28 subjects at a mean \pm SE interval of $79.2 \pm 8.8$ days after induced sputum. On the day of monitoring there was no difference in background PM10 or meteorological variables between cyclists and non-cyclists (table 2).

The mean exposure/time plots for the two groups showed the highest $\mathrm{BC}$ exposure to have occurred during the day and the lowest exposure occurred at night (fig. 2). There was no difference in either $24 \mathrm{~h} \mathrm{BC}$, home BC, or exposure to BC during other periods, between cyclists and non-cyclists (table 2). However, commuting BC was 2.6-fold higher in cyclists $(\mathrm{p}<0.01)$ (table 2), and a higher fraction of 24-h BC exposure was associated with commuting in cyclists $(41 \pm 3.4 \%$ versus $18 \pm 4.2 \% ; \mathrm{p}<0.001$ ) (fig. 3 ). Increased commuting $\mathrm{BC}$ in cyclists was due to a combination of increased time commuting $(\mathrm{p}<0.01)$ (table 2), and higher BC on the roads used for commuting $\left(11,681 \pm 1,375\right.$ versus $7,135 \pm 1,714 \mathrm{ng} \cdot \mathrm{m}^{-3}$ per $\left.5 \mathrm{~min} ; \mathrm{p}<0.05\right)$. Maximum peak BC always occurred during commuting in both groups, but the maximum peak concentration was higher in cyclists $(\mathrm{p}<0.05)$ (table 2$)$.

Compatible with our previous data from healthy children [13], there was marked intra-subject variation in carbon loading in

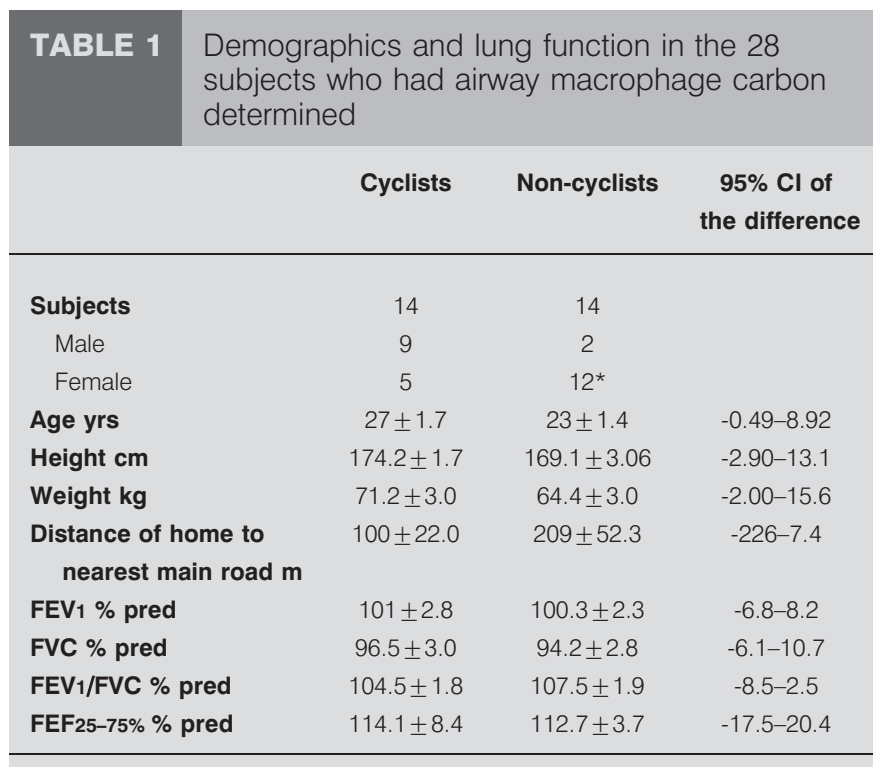

Data are presented as $\mathrm{n}$ or mean $\pm \mathrm{SE}$, unless otherwise stated. Data are compared using unpaired t-tests. Lung function was performed 10 min post inhaled bronchodilator (salbutamol $400 \mu \mathrm{g}$ ). FEV1: forced expiratory volume in $1 \mathrm{~s}$; \% pred: \% predicted; FVC: forced vital capacity; FEF25-75\%: forced expiratory flow at $25-75 \%$ of FVC. *: $p<0.05$ by Chi-squared test.

AM carbon loading in both cyclists and non-cyclists (fig. 4). Cyclists had 1.6-fold higher AM carbon compared with noncyclists $\left(1.81 \pm 0.21\right.$ versus $1.11 \pm 0.07 \mu \mathrm{m}^{2}, 95 \%$ CI $0.22-1.17$; $\mathrm{p}<0.01$ ) (fig. 5). AM carbon was associated with commuting $B C(n=27 ; r=0.47 p<0.05)$, but was not associated with either $\mathrm{BC}$ exposure at home or $\mathrm{BC}$ exposure during non-commuting activities (other BC). There was no association between AM carbon and age $(\mathrm{r}=0.16, \mathrm{p}=$ not significant $)$.

There was no difference in systemic GM-CSF, IL-1 $\beta$, IL-2, IL-6 and IL- 8 between cyclists and non-cyclists (table 3 ). However, cyclists $(n=14)$ had higher TNF- $\alpha$ when compared with noncyclists $(n=12 ; p<0.05)$ (table 3$)$.

\section{DISCUSSION}

In this study of healthy Londoners who regularly commute to work by either bicycle, or public transport/walking, we sought to test the hypothesis that commuting by bicycle is associated with an increased long-term inhaled dose of BC. Using the area of BC in AMs as a marker of the long-term "internal" dose of $\mathrm{BC}$, we found that cyclists had a 1.6-fold higher AM carbon compared with commuters using public transport. Short-term personal monitoring of "external" exposure to BC performed after AM carbon analysis showed no difference in $24 \mathrm{~h} \mathrm{BC}$ between cyclists and non-cyclists. However, cyclists spent longer commuting and, therefore, had 2.6-fold higher commute BC. These results suggest that: 1) exposure to BC during commuting has a disproportionate influence on AM carbon; and 2) short-term monitoring provides insights into long-term inhaled BC dose when behaviour is habitual. In a recent study on the effect of mode of commute on exposure to air pollution, ZUURBIER et al. [6] reported that cyclists using commuting routes in Arnhem (the Netherlands) were not exposed to increased levels of BC (soot) compared with subjects using 
TABLE 2 Short-term personal black carbon (BC) exposure data from cycling and non-cycling adults

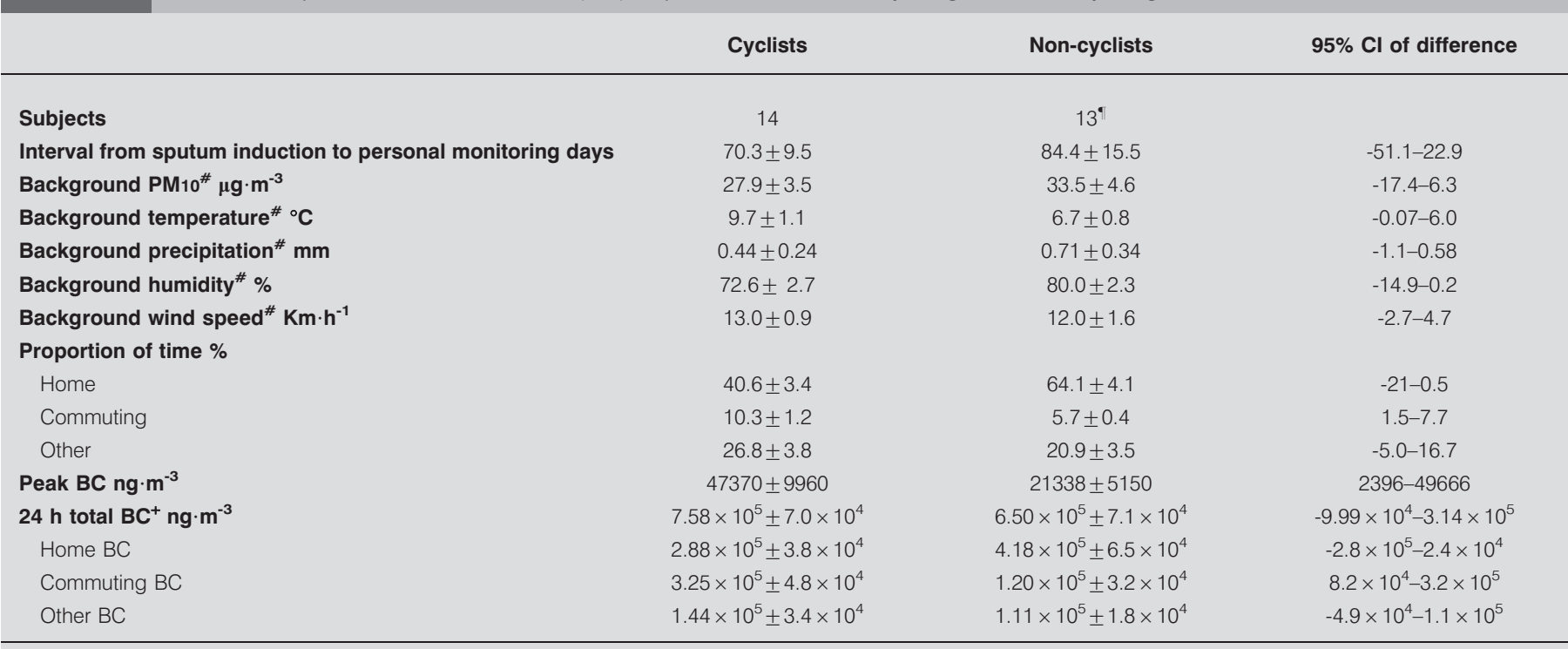

Data are presented as $\mathrm{n}$ or mean $\pm \mathrm{SE}$, unless otherwise stated. Data are compared using unpaired t-tests. $\mathrm{BC}$ monitoring was carried out on a representative working day (24 h) after assessment of airway macrophage carbon. BC exposure during specific activities was determined from a time/activity diary completed on the day of monitoring. PM10: particulate matter $<10 \mu \mathrm{m}$ in aerodynamic diameter. ${ }^{*}$ : expressed as $24 \mathrm{~h}$ mean for each subject's day of monitoring; ": personal monitoring was not carried out in one subject with airway macrophage carbon; ${ }^{+}$: BC is the sum of BC concentrations for each 5-min period monitored by the aethalometer on a representative working day.

public transport, but when the effect of $V^{\prime} E$ was considered, cycling was associated with increased modelled inhaled BC dose [6]. The increased AM carbon in cyclists is compatible with the hypothesis that exercise increases inhaled BC dose.
However, cyclists in our study had a free choice of route, and therefore commuted for longer and were exposed to higher levels of $\mathrm{BC}$ on their commute. Therefore, we cannot assess the independent contribution of cycling/increased $V^{\prime}$ E per se on

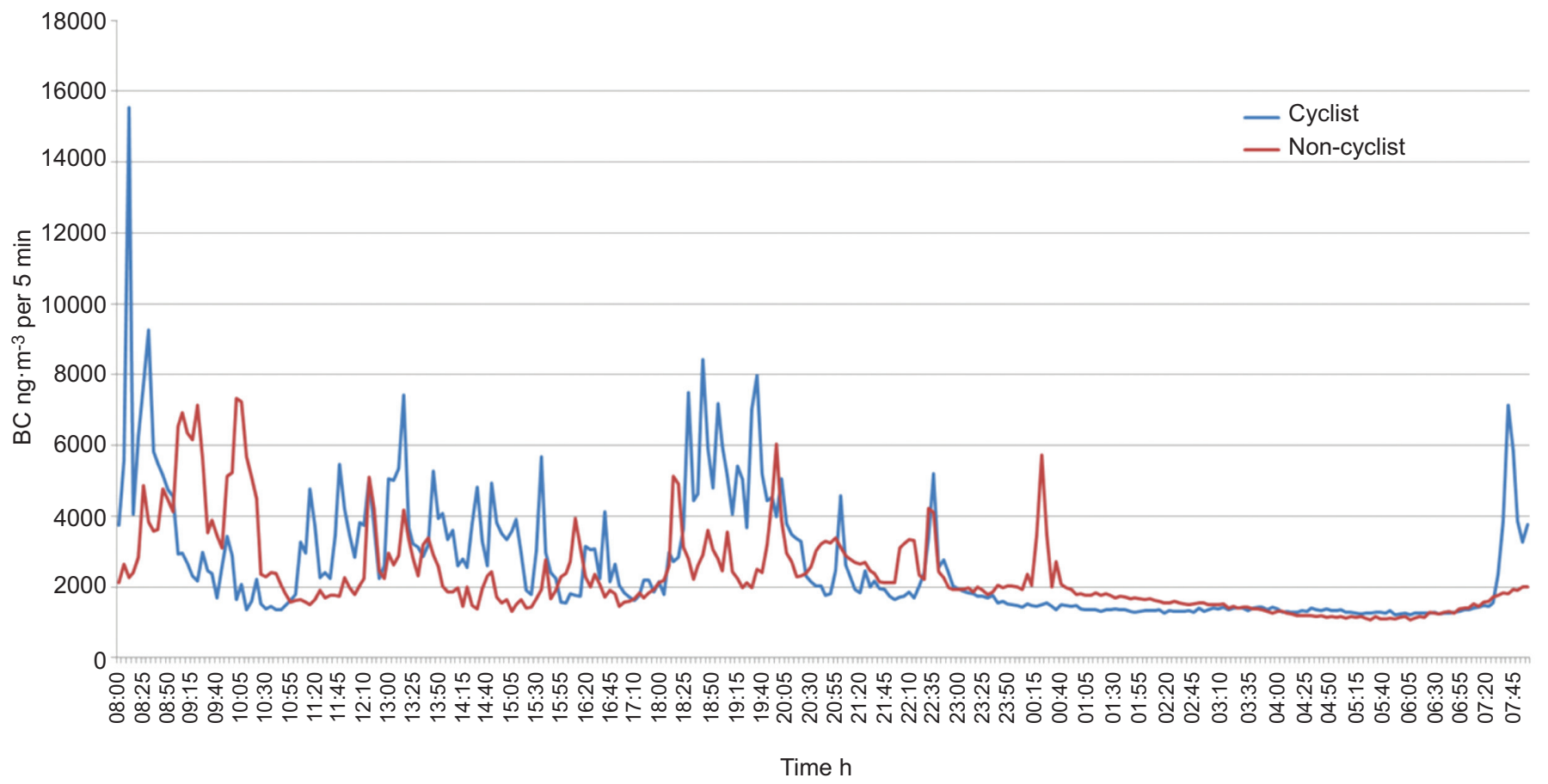

FIGURE 2. Personal black carbon (BC) monitored using a portable aethalometer in 14 cyclists and 13 non-cyclists. Data are represented as the mean $B C$ exposure for each group. Exposure to $\mathrm{BC}$ is low in both groups when subjects were at home. 
a)
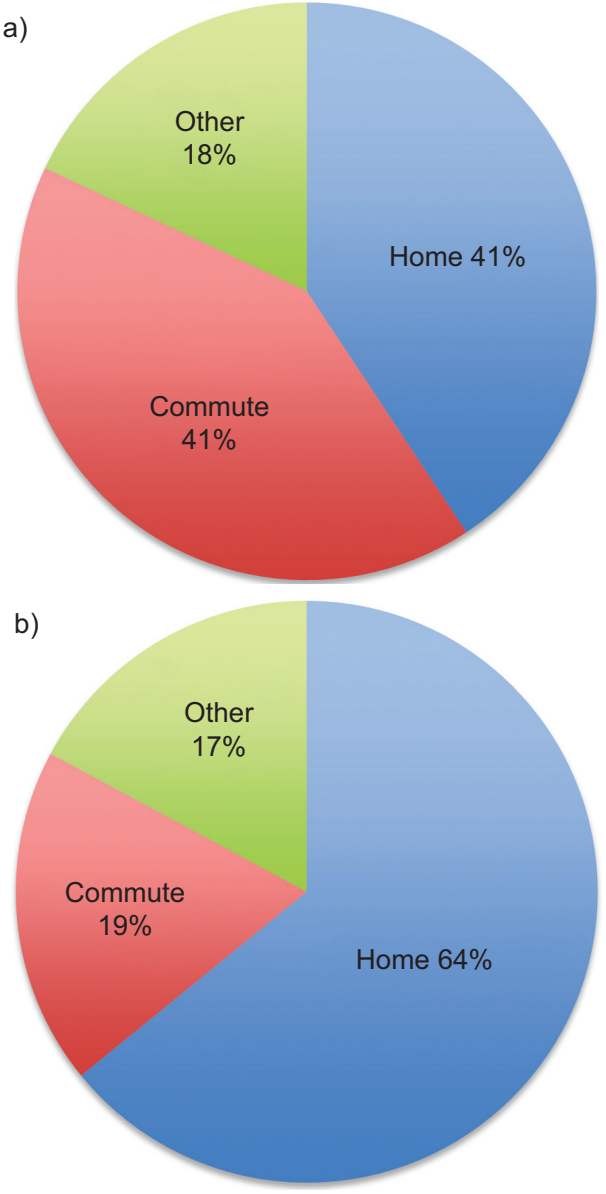

FIGURE 3. The mean proportion of $24 \mathrm{~h}$ black carbon (BC) exposure at home, during the commute and during non-commuting time (other) in a) cyclists ( $n=14)$ and b) non-cyclists $(n=13)$. BC exposure was the sum of mean $B C\left(n g \cdot m^{-3}\right)$ for each 5-min period. Activity was determined from a diary completed on the day of monitoring. A greater proportion of $24 \mathrm{~h} \mathrm{BC}$ exposure in cyclists was from the commute $(p<0.001$ versus non-cyclists).

AM carbon. An alternative explanation why exposure to BC during commuting, but not at other times, is associated with AM carbon is that high peaks of BC from freshly generated exhaust fumes, evade the filtering mechanisms of the upper airway. Indeed the individual plots of BC exposure of cyclists show very high BC peaks during the commute (fig. S1). Further studies are required to assess the effect of BC peaks on $\mathrm{AM}$ carbon; since this may also be relevant to the inhaled dose of $\mathrm{BC}$ from indoor environmental cigarette smoke, and indoor biomass smoke.

Epidemiological studies suggest that individual exposure to fossil fuel-derived BC should be as low as practicable. For example, a meta-regression analysis of triggers of myocardial infarction, found that the highest attributable population fraction was for exposure to traffic emissions; followed by physical exercise [25]. In addition, a population-based study found that BC concentration over a 5-yr period at the home address was associated with increased hospitalisation for coronary heart disease, and increased chronic heart-disease mortality after adjusting for age, sex, pre-existing co-morbidity, neighbourhood

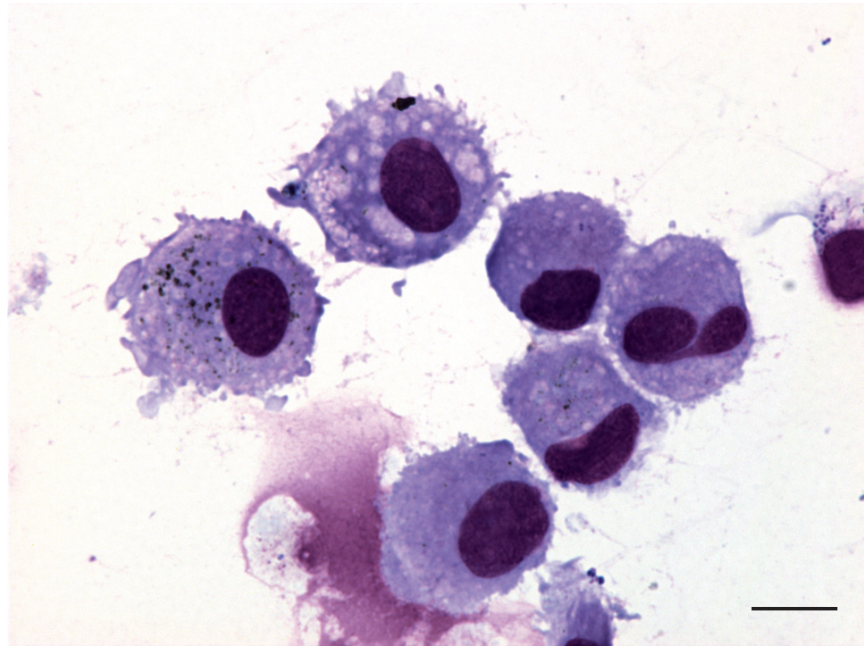

FIGURE 4. Airway macrophages (AMs) from a cyclist. There is marked heterogeneity in uptake of carbon by AMs (black areas in the cytoplasm). AMs were imaged under light microscopy. Scale bar $=10 \mu \mathrm{m}$.

socioeconomic status, and $\mathrm{PM} 2.5$ and $\mathrm{NO}_{2}$ [7]. Exposure to $\mathrm{BC}$ is also associated with surrogates for health effects in healthy adults. For example, McCRACKEN et al. [26] studied telomere length, a marker of cellular ageing [27], and found that increased annual BC exposure was associated with decreased telomere length in healthy nonsmoking males. Whether increased levels of AM carbon in healthy London cyclists is a risk factor for future health effects is unknown, but in nonsmoking diabetic adults, JACOBS et al. [14] reported that a $7.2 \mathrm{U} \cdot \mathrm{L}^{-1}$ increase in plasma oxidised low-density lipoprotein (a risk factor for coronary artery disease [28]), was associated with each $0.25 \mu \mathrm{m}^{2}$ increase in AM carbon. We did not measure lipoproteins, but it is interesting to note that the $95 \%$ CI for the difference in AM carbon between cyclists and non-cyclists in the present study is between 0.22 and $1.17 \mu \mathrm{m}^{2}$. The moderate increase in serum TNF- $\alpha$ in cyclists in the present study does provide preliminary evidence of a downstream systemic effect of inhaled BC. These

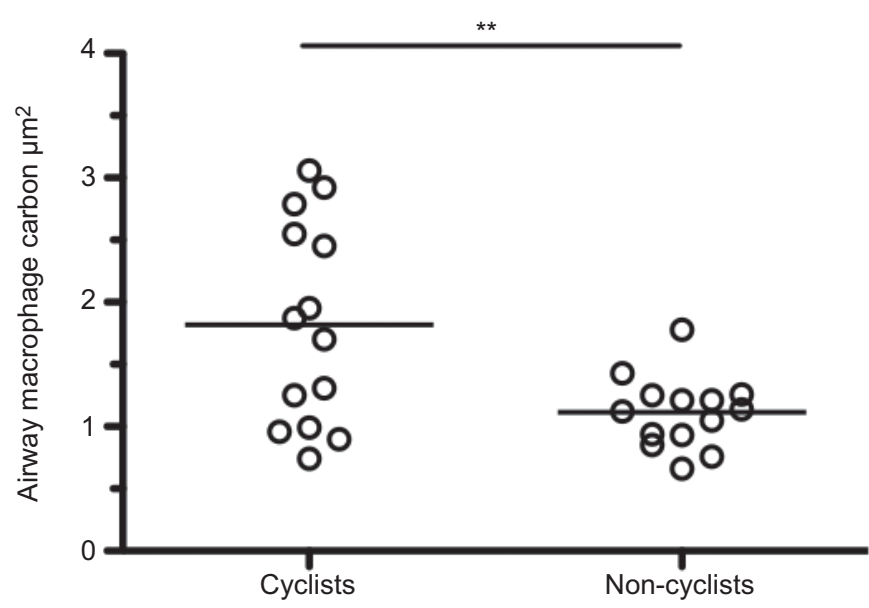

FIGURE 5. Airway macrophage carbon in cyclists and non-cyclists. Line represents mean. For each subject, the mean airway macrophage carbon was determined from 50 randomly imaged cells. ${ }^{* *}: p<0.01$. 


\begin{tabular}{|c|c|c|c|}
\hline \multirow[t]{2}{*}{ TABLE 3} & \multirow[b]{2}{*}{ Cyclists } & \multirow[b]{2}{*}{ Non-cyclists } & \multirow[b]{2}{*}{$\begin{array}{l}95 \% \mathrm{Cl} \text { of } \\
\text { difference }\end{array}$} \\
\hline & & & \\
\hline Subjects n & 14 & 14 & \\
\hline $\begin{array}{l}\text { Airway macrophage } \\
\text { carbon } \mu \mathrm{m}^{2}\end{array}$ & $1.81 \pm 0.21$ & $1.11 \pm 0.07$ & $0.22-1.17$ \\
\hline $\mathrm{GM}-\mathrm{CSF} \mathrm{pg} \cdot \mathrm{mL}^{-1}$ & $1.04 \pm 0.65$ & $0.59 \pm 0.19$ & $-1.05-1.94$ \\
\hline $\mathrm{IL}-1 \beta \mathrm{pg} \cdot \mathrm{mL}^{-1}$ & $0.68 \pm 0.12$ & $1.11 \pm 0.22$ & $-0.93-0.69$ \\
\hline $\mathrm{IL}-2 \mathrm{pg} \cdot \mathrm{mL}^{-1}$ & $2.07 \pm 0.52$ & $0.74 \pm 0.46$ & $-0.14-2.78$ \\
\hline $\mathrm{IL-}-6 \mathrm{pg} \cdot \mathrm{mL}^{-1}$ & $0.84 \pm 0.06$ & $0.98 \pm 0.22$ & $-0.59-0.30$ \\
\hline $\mathrm{IL-8} \mathbf{p g} \cdot \mathrm{mL}^{-1}$ & $3.73 \pm 0.22$ & $4.56 \pm 0.69$ & $-2.25-0.59$ \\
\hline TNF- $\alpha \mathrm{pg} \cdot \mathrm{mL}^{-1}$ & $7.18 \pm 0.39$ & $5.99 \pm 0.29$ & $0.14-2.23$ \\
\hline
\end{tabular}

data are compatible with TöRNQVIST et al. [29], who reported increased serum TNF- $\alpha$ in healthy adults $24 \mathrm{~h}$ after inhalation of $300 \mu \mathrm{g} \cdot \mathrm{m}^{-3}$ diesel exhaust PM; however, our TNF- $\alpha$ data should be interpreted with caution. First, multiple cytokine testing of a small number of subjects increases the possibility of type I error. Secondly, we found no significant association between serum TNF- $\alpha$ and either commute BC, or $24 \mathrm{~h} \mathrm{BC}$, or AM carbon.

There are limitations to our study. For example, it is unclear whether AM carbon reflects the dose of BC inhaled over weeks, months, or even years. It is, however, unlikely that AM carbon exclusively reflects short-term inhaled BC dose. First, in rats there is a strong association between AM carbon and long-term inhaled BC dose [12]. Secondly, in Malawian adults we found that AM carbon tracks closely with the BC-generating potential of the fuel regularly used in the home for cooking [30]. Thirdly, the lifespan of AM in the lower airway, and therefore its ability to acquire inhaled BC, is up to several months [31]. A further limitation is that there was a sex imbalance between cyclists and non-cyclists in the present study. This imbalance reflects cycling behaviour in London, where male cyclists make twice as many trips than females in the 25-44 yr age range [32]. An effect of sex on AM carbon is unlikely since: 1) we previously found no association between sex and AM carbon in healthy adolescents [13]; 2) JACOBS et al. [15] found no association between AM carbon and sex in a large study of adult diabetic patients; and 3) there was no significant difference in AM carbon between males and females (unpaired t-test).

In summary, cycling to work in London is associated with increased AM carbon compared with travelling to work by public transport and/or walking. Increased AM carbon in cyclists is due, in part, to the longer time taken to travel to work and exposure to high local concentrations of BC. Personal BC monitoring is a promising method for planning personal commute routes, but interpreting these data is not straightforward. For example, cycling to work by a low traffic-density road will certainly reduce commute $\mathrm{BC}$ per unit time, but if travel time increases, total commute $\mathrm{BC}$ exposure may remain the same. In conclusion, cycling to work in London is associated with increased long-term inhaled dose of BC. Whether increased $V^{\prime} \mathrm{E}$ associated with cycling is an independent risk factor for increased inhaled BC remains unclear.

\section{SUPPORT STATEMENT}

Funding support was received from Barts and the London Charity.

\section{STATEMENT OF INTEREST}

Statements of interest for C. Nwokoro and J. Grigg can be found at www.erj.ersjournals.com/site/misc/statements.xhtml

\section{ACKNOWLEDGEMENTS}

Some of these study data were presented as an abstract at the 2011 European Respiratory Society congress in Amsterdam, the Netherlands.

\section{REFERENCES}

1 Gauderman WJ, Avol E, Gilliland F, et al. The effect of air pollution on lung development from 10 to 18 years of age. N Engl J Med 2004; 351: 1057-1067.

2 Brunekreef B, Beelen R, Hoek G, et al. Effects of long-term exposure to traffic-related air pollution on respiratory and cardiovascular mortality in the Netherlands: the NLCS-AIR study. Res Rep Health Eff Inst 2009; 139: 5-71.

$3 \mathrm{Knol} \mathrm{AB}$, de Hartog JJ, Boogaard H, et al. Expert elicitation on ultrafine particles: likelihood of health effects and causal pathways. Part Fibre Toxicol 2009; 6: 19.

4 Kocbach A, Johansen BV, Schwarze PE, et al. Analytical electron microscopy of combustion particles: a comparison of vehicle exhaust and residential wood smoke. Sci Total Environ 2005; 346: 231-243.

5 Janssen NA, Hoek G, Simic-Lawson M, et al. Black carbon as an additional indicator of the adverse health effects of airborne particles compared to PM10 and PM2.5. Environ Health Perspect 2011; 119: 1691-1699.

6 Zuurbier M, Hoek G, Oldenwening M, et al. Commuters' exposure to particulate matter air pollution is affected by mode of transport, fuel type, and route. Environ Health Perspect 2010; 118: 783-789.

7 Gan WQ, Koehoorn M, Davies HW, et al. Long-term exposure to traffic-related air pollution and the risk of coronary heart disease hospitalization and mortality. Environ Health Perspect 2011; 119: 501-507.

8 Bayer-Oglesby L, Schindler C, Hazenkamp-von Arx ME, et al. Living near main streets and respiratory symptoms in adults: the Swiss Cohort Study on Air Pollution and Lung Diseases in Adults. Am J Epidemiol 2006; 164: 1190-1198.

9 Zuurbier M, Hoek G, van den Hazel P, et al. Minute ventilation of cyclists, car and bus passengers: an experimental study. Environ Health 2009; 8: 48.

10 Johan de Hartog J, Boogaard H, Nijland H, et al. Do the health benefits of cycling outweigh the risks? Environ Health Perspect 2010; 118: 1109-1116.

11 Rojas-Rueda D, de Nazelle A, Tainio M, et al. The health risks and benefits of cycling in urban environments compared with car use: health impact assessment study. BMJ 2011; 343: d4521.

12 Finch GL, Hobbs $\mathrm{CH}$, Blair LF, et al. Effects of subchronic inhalation exposure of rats to emissions from a diesel engine burning soybean oil-derived biodiesel fuel. Inhal Toxicol 2002; 14: 1017-1048.

13 Kulkarni N, Pierse N, Rushton L, et al. Carbon in airway macrophages and lung function in children. N Engl J Med 2006; 355: 21-30.

14 Jacobs L, Emmerechts J, Hoylaerts MF, et al. Traffic air pollution and oxidized LDL. PLoS One 2011; 6: e16200. 
15 Jacobs L, Emmerechts J, Mathieu C, et al. Air pollution related prothrombotic changes in persons with diabetes. Environ Health Perspect 2010; 118: 191-196.

16 Nwokoro C, Mushtaq N, Harrison C, et al. Inhaled black carbon in the lower airways of London cyclists. Eur Respir J 2011; 38: Suppl. $55,184 \mathrm{~s}$.

17 Free Maps Tools. www.freemaptools.com/measure-distance.htm Date last updated: October 2010. Date last accessed: January 5, 2012.

18 Standardization of Spirometry, 1994 Update. American Thoracic Society. Am J Respir Crit Care Med 1995; 152: 1107-1136.

19 Environmental Research Group, King's College London. www. londonair.org.uk/london/asp/datadownload.asp Data last updated: January 1, 2012. Date last accessed: January 5, 2012.

20 Weather Underground Inc. Wunderground.com. www.wunderground.com/history/london/EGLL/ Date last updated: January 4, 2012. Date last accessesd: January 5, 2012.

21 Boland S, Baeza-Squiban A, Fournier T, et al. Diesel exhaust particles are taken up by human airway epithelial cells in vitro and alter cytokine production. Am J Physiol 1999; 276: L604-L613.

22 Alfaro-Moreno E, Nawrot TS, Vanaudenaerde BM, et al. Cocultures of multiple cell types mimic pulmonary cell communication in response to urban PM10. Eur Respir J 2008; 32: 1184-1194.

23 Omara FO, Fournier M, Vincent $\mathrm{R}$, et al. Suppression of rat and mouse lymphocyte function by urban air particulates (Ottawa dust) is reversed by $\mathrm{N}$-acetylcysteine. J Toxicol Environ Health $A$ 2000; 59: 67-85.

24 Ishii H, Fujii T, Hogg JC, et al. Contribution of IL-1 $\beta$ and TNF- $\alpha$ to the initiation of the peripheral lung response to atmospheric particulates (PM10). Am J Physiol Lung Cell Mol Physiol 2004; 287: L176-L183.

25 Nawrot TS, Perez L, Kunzli N, et al. Public health importance of triggers of myocardial infarction: a comparative risk assessment. Lancet 2010; 377: 732-740.

26 McCracken J, Baccarelli A, Hoxha M, et al. Annual ambient black carbon associated with shorter telomeres in elderly men: Veterans Affairs Normative Aging Study. Environ Health Perspect 2010; 118: 1564-1570.

27 Mather KA, Jorm AF, Parslow RA, et al. Is telomere length a biomarker of aging? A review. J Gerontol A Biol Sci Med Sci 2011; 66: 202-213.

28 Tsimikas S, Brilakis ES, Miller ER, et al. Oxidized phospholipids, Lp(a) lipoprotein, and coronary artery disease. N Engl J Med 2005; 353: 46-57.

29 Törnqvist H, Mills NL, Gonzalez M, et al. Persistent endothelial dysfunction in humans after diesel exhaust inhalation. Am J Respir Crit Care Med 2007; 176: 395-400.

30 Fullerton DG, Jere K, Jambo K, et al. Domestic smoke exposure is associated with alveolar macrophage particulate load. Trop Med Int Health 2009; 14: 349-354.

31 Wilson AA, Murphy GJ, Hamakawa H, et al. Amelioration of emphysema in mice through lentiviral transduction of longlived pulmonary alveolar macrophages. J Clin Invest 2010; 120: 379-389.

32 Transport for London. London Travel Report 2007. www.tfl.gov.uk/ assets/downloads/corporate/London-Travel-Report-2007-final.pdf Date last accessed: January 5, 2012. 